\title{
Florence Nightingale e as irmãs de caridade: revisitando a história
}

\author{
Florence Nightingale and charity sisters: revisiting the history \\ Florence Nightingale y las hermanas de caridad: revisitando la historia
}

\section{Maria Itayra Coelho de Souza Padilha}

Doutora em Enfermagem pela Escola de Enfermagem Anna Nery/UFRJ. Professor Adjunto do Departamento de Enfermagem da Universidade Federal de Santa Catarina/ Brasil. Sub-Coordenadora do Grupo de Estudos da História do Conhecimento da Enfermagem(GEHCE). Pesquisadora do padilha@nfr.ufsc.br

\section{Joel Rolim Mancia}

Enfermeiro do Hospital de Pronto Socorro de Porto Alegre-RS. Mestre em Enfermagem. Aluno do Curso de Doutorado do Programa de Pós-Graduação em Enfermagem da Universidade Federal de Santa Catarina.

Membro do Grupo de Estudos da História do Conhecimento da Enfermagem(GEHCE). joelmancia@uol.com.br

\section{RESUMO}

O estudo trata de uma reflexão historiográfica acerca dos elos de ligação entre a prática de enfermagem e a influência recebida das ordens/associações religiosas, que marcam o ideário de enfermagem até os dias de hoje, especialmente das Irmãs de Caridade de São Vicente de Paulo. A enfermagem profissional, que só ocorreria no século XIX na Inglaterra, erigida por Florence Nightingale sofreria influência direta dos ensinamentos de amor e fraternidade traduzidos pelo conceito de altruísmo, da valorização do ambiente adequado para o cuidado e a divisão social do trabalho em enfermagem. O estudo mostra também a influência sofrida por Florence Nightingale pelo trabalho exercido pelas Irmãs de Caridade.

Descritores: Enfermagem; Historia da enfermagem; Caridade.

\section{ABSTRACT}

This study presents an historical analysis on the links betwen the nursing practice and the influence received from various religious orders/associations along the times, especially from Saint Vincent Paul's charity sisters. The professional nursing which was pioneered by Florence Nightingale in the XIXth century, was directly influenced by the teachings of love and fraternity. In addition, other contributions from the religious orders/associations were the concepts of altruism, valorization of an adequate environment for the care of patients, and the division of work in nursing. The study shows the influence of Charity Sisters on Florence Nightingale.

Descriptors: Nursing, Nursing history; Charity.

\section{RESUMEN}

El estudio trata de una reflexión historiográfica acerca de los eslabones de conexión entre la práctica de enfermería y la influencia recibida de las órdenes/asociaciones religiosas, que marcan el ideario de enfermería hasta los días de hoy, especialmente de las Hermanas de la Caridad de San Vicente de Pablo. La enfermería profesional, que sólo se llevaría a cabo en el siglo XIX en Inglaterra, erigida por Florence Nightingale sufriría influencia directa de las enseñanzas de amor y fraternidad traducidos por el concepto de altruismo, de la valorización del ambiente adecuado para el cuidado y la división social del trabajo en enfermería. El estudio mostra también la influencia sufrida por Florence Nightingale por el trabajo ejercido por las hermanas de la Caridad. Descriptores: Enfermería; Historia de la enfermería; Caridad.

Padilha MICS, Mancia JR. Florence Nigthingale e as irmãs de caridade: revisitando a história. Rev Bras Enferm 2005 nov-dez; 58(6):723-6.

\section{INTRODUZINDO A HISTÓRIA}

A enfermagem profissional no mundo foi erigida a partir das bases científicas propostas por Florence Nightingale, que foi influenciada diretamente pela sua passagem nos locais onde se executava o cuidado de enfermagem leigo e fundamentado nos conceitos religiosos de caridade, amor ao próximo, doação, humildade, e também pelos preceitos de valorização do ambiente adequado para o cuidado, divisão social do trabalho em enfermagem e autoridade sobre o cuidado a ser prestado.

O cuidado dos enfermos foi uma das muitas formas de caridade adotadas pela igreja e que se conjuga à história da enfermagem, principalmente após o advento do cristianismo. Os ensinamentos de amor e fraternidade transformaram não somente a sociedade, mas também o desenvolvimento da enfermagem, marcando, ideologicamente, a prática de cuidar do outro e modelando comportamentos que atendessem a esses ensinamentos.

A enfermagem profissional sofreria influência direta destes ensinamentos, traduzida pelo conceito de altruísmo introduzido pelos primeiros cristãos. O termo altruísmo deriva da palavra latina alter 
(outro), e por isso o significado de altruísmo foi o de pensar nos demais e interessar-se por eles ${ }^{(1)}$. Este termo não era uma idéia nova, porém pode-se dizer que era uma idéia velha com novas motivações.

A caridade era 0 amor a Deus em ação, propiciando para aqueles que a praticavam o fortalecimento de caráter, a purificação da alma e um lugar garantido no céu. $O$ cuidado dos enfermos, embora não fosse a única forma de caridade prestada, elevou-se a um plano superior, isto é, o que era um trabalho praticado apenas por escravos, se converteu em uma vocação sagrada e passou a ser integrado por homens e mulheres cristãos(ãs). Embora haja controvérsias sobre a elevação ou não da posição das mulheres pelo cristianismo, a opinião comum é de que 0 cristianismo propiciou às mulheres oportunidades para exercer um trabalho social honrado e ativo, particularmente para as mulheres solteiras elou viúvas, no cuidado aos pobres e aos doentes ${ }^{(2)}$.

Com o advento do cristianismo, também começaram a ser criadas as ordens cristãs. Na primeira era cristã (até 500 DC) uma das primeiras ordens de mulheres trabalhadoras foram as diaconisas e as viúvas. Mais tarde, incorporaram-se as virgens, as presbiterianas, as canônicas, as monjas e as irmãs de caridade ${ }^{(1)}$.

Pretendemos com este estudo, estabelecer uma reflexão sobre os elos de ligação entre a prática de enfermagem proposta a partir de Florence Nightingale e a influência recebida das ordens/associações religiosas, mais especificamente a Companhia das Irmãs de Caridade de São Vicente de Paulo.

\section{LUISA DE MARILLAC E OS RITUAIS DO CUIDADO}

Uma das organizações que surgiu no século XVII e que mantém seu trabalho até os dias de hoje é a Companhia das Irmãs de Caridade, fundada no ano de 1633, na França, por padre Vicente de Paulo (15761660) e Luisa de Marillac (1591-1660). Esta Companhia foi criada em um momento em que a miséria e as doenças causadas pelas contínuas guerras estavam aniquilando a França, e as agitações políticas eram uma constante. Padre Vicente de Paulo era um sacerdote católico da Ordem de São Francisco de Assis, francês, calado e modesto, que desde sua introdução na igreja preocupava-se com a situação de abandono dos pobres franceses. Luisa de Marillac era proveniente de família abastada e, após enviuvar, resolveu dedicar sua vida aos pobres e aos doentes ${ }^{(3)}$.

O trabalho da Companhia era o de alimentar os pobres, cuidar dos doentes nos hospitais, ir aos domicílios daqueles que necessitassem e realizar o trabalho paroquial. Foi uma das primeiras associações a realizar cuidados de enfermagem no domicílio, inaugurando um serviço importante de assistência social. Também reorganizaram os hospitais, implantando a higiene no ambiente, individualizando os leitos dos enfermos e dirigindo todo o cuidado desenvolvido no hospital.

A primeira superiora foi Luisa de Marillac, que devia receber as jovens aldeãs que quisessem consagrar-se a Deus para tratarem dos doentes, formá-las na piedade, ensinar-lhes a curar as feridas e fazer o serviço dos pobres, com a liberdade de mudá-las de paróquia e de ofício e de despedir as que não tivessem as qualidades necessárias para estas funções. A intenção inicial era a manutenção do trabalho executado até então pela Confraria da Caridade, isto é, ajudar aos pobres e doentes nas paróquias e domicílios, e não nos hospitais. A Confraria da Caridade havia sido fundada em 1617 por Vicente de Paulo e era composta por Senhoras da alta sociedade parisiense que desejavam servir aos pobres e doentes da cidade. A Companhia das Irmãs de Caridade foi fundada para suprir as necessidades de mulheres que apenas servissem os pobres, sem outro compromisso como o casamento, família, dentre outros ${ }^{(3)}$.

Era necessário que houvesse mulheres que se responsabilizassem unicamente pelo "pão dos pobres enfermos, alimentação e os remédios, segundo a exigência de suas enfermidades"(4), de forma pacífica e passiva, sem outros compromissos que as impedissem de cuidar dos pobres. Chamaram moças camponesas de Paris e arredores mostrando desejo de servir os pobres de cada confraria da capital, sob a vigilância inicial das prioras e depois sob a direção de uma superiora comum, para instruí-las nos exercícios da piedade e no modo de tratar dos pobres.

A razão pela qual padre Vicente de Paulo e Luisa de Marillac chamaram estas aldeãs está claramente expressa no discurso de que, ambos durante suas andanças, haviam encontrado "donzelas sem inclinação para o casamento nem recursos para abraçar a vida religiosa, mas dispostas a se dedicarem às obras de caridade"(5).

As atividades tinham como objetivo o de auxiliar as Senhoras das Confrarias no cuidado aos pobres e doentes, principalmente naqueles trabalhos que thes era mais custoso fazer, isto é, cuidado àqueles dos hospitais e domicílios. 0 treinamento devia ser de poucas palavras, nenhuma explicação, e o máximo de silêncio, interrompido por exercícios de catequese e cuidados domésticos e caridade. Um simples olhar, gestos, palmas deviam "significar em sua brevidade a técnica de comando e a moral da obediência"(6).

O exercício da disciplina supõe um dispositivo que obrigue pelo "jogo do olhar"(7), uma forma onde as técnicas que permitem ver induzam a efeitos de poder. É ao mesmo tempo silencioso e "discreto", mas absolutamente indiscreto porque está presente o tempo todo, em cada canto e lugar. Uma irmã supervisiona e controla a ação da outra e é controlada por esta, e todas são "olhadas" e "vigiadas" pela Superiora. Durante os primeiros dez anos, a Companhia não tinha Regulamento definitivo e pouco a pouco 0 que era prática, tornava-se tradição e 0 ritual do cuidado era passado de uma a outra, conforme iam aprendendo $a$ arte de ser enfermeira.

Tinham como primeiro princípio, o de que Deus Ihes entregou "nas pessoas dos pobres velhos, crianças, doentes, prisioneiros e outras mulheres, todos os serviços, sejam corporais, sejam espirituais,(...) e ainda que não sejam religiosas"(4), devem portar-se como tal, guardando uma vida perfeita de recolhimento, castidade e abstenção de toda a leviandade terrena. Além disso, deviam se guardar ao máximo de qualquer contato com o sexo masculino, mesmo quando se encontravam doentes, ou quando iam cuidar de homens doentes.

O espírito de doação, a abnegação, a castidade despontam como prioridades nas exigências àquelas que iriam cuidar do corpo do outro, naquelas que seriam enfermeiras. Com relação aos doentes que cuidam devem "levá-los a confessar seus pecados" antes de morrer e caso recuperem a saúde, são induzidos a consagrar-se a Deus que thes recuperou a saúde. 0 plano de conduta das Irmãs de Caridade prescrevia sempre o serviço espiritual aliado aos cuidados corporais de enfermagem, devendo ambos ser realizados com muita "humildade". Todas as candidatas a irmãs de caridade deveriam aprender as três virtudes formadoras da alma das irmãs: a humildade, a simplicidade e a caridade $^{(3)}$.

Luisa de Marillac e padre Vicente de Paulo levaram a confraria da alta nobreza de Paris aos leitos dos doentes do Hôtel - Dieu. Este grande hospital estava sob a dependência dos cônegos da Catedral e o serviço interno era dirigido pelas irmãs agostinianas. Embora houvesse aí perto de 150 religiosas, das quais 50 eram noviças, esta imensa casa de dores era um lugar horrível e infecto, sem leitos brancos e limpos, sem uma disciplina minuciosa, com alimentação insuficiente, e a assistência religiosa quase nula. Entretanto, o número de doentes era enorme, sempre acima de 1200 , chegando a 2000. As camas eram quase encostadas umas as outras e comuns a vários doentes, chegando a conter cada uma seis doentes, três deitados em um sentido e três no outro. A confraria da caridade contava com mais de 200 senhoras, inclusive a rainha da França, Maria de Médicis. Padre Vicente de Paulo foi nomeado diretor de todo serviço espiritual do Hospital e a mesa 
diretora foi formada e coordenada pelas senhoras da Confraria da Caridade.

As senhoras, iam ao Hôtel-Dieu á uma hora depois do meio dia e lá ficavam até às quatro. Depois de uma visita ao Santíssimo sacramento, punham um avental branco, e por grupos de quatro, dividiam entre sí as diversas salas, onde elas passavam de uma cama á outra para oferecerem aos enfermos alimentos conforme a estação. ( ...) As irmãs de caridade SEGUIAM as Senhoras LEVANDO as bandejas e os pratos, AJUDANDO as senhoras nas distribuições ${ }^{(8)}$.

As atitudes das irmãs de caridade eram de submissão e sujeição àquelas que assumiam a responsabilidade pelo cuidado. De uma forma simplista, ia se estabelecendo uma divisão social de classe e de trabalho, como se evidencia a seguir quando algumas Senhoras da Confraria se ressentem da presença das irmãs, "pessoas de modos simples" e passam a propagar a idéia de que aquele serviço só deveria ser realizado por pessoas "formadas de bom-tom, e que só parisienses estavam a altura daquele serviço". Porém, aos poucos percebem que "as jovens da cidade têm mais urbanidade, mas as dos campos eram mais sinceras e delicadas, e que o melhor era não fazer distinção"(8). Assim, o trabalho considerado braçal, mas que se constituía no cuidado de enfermagem, era realizado pelas irmãs de caridade e supervisionado pelas Senhoras da Confraria. Desta forma, os rituais do cuidado iam se construindo como um corpo de conhecimentos, sendo executados por pessoas específicas e ordenados por outras.

A mola mestra no cuidado aos doentes no hospital era a salvação das almas, tanto dos pobres no momento da morte, quanto daqueles que cuidavam dos mesmos ${ }^{(6)}$. 0 espírito de servir e o compromisso com a caridade era suficiente para a identificação daquelas que seriam "enfermeiras", e reconhecidas como tal pelas suas atitudes.

O regulamento a ser seguido pelas Irmãs de Caridade enfermeiras foi elaborado quando as irmãs passaram a atuar em outros hospitais da França, sendo o primeiro deles o Hospital São João, da cidade de Angers, que serviu de modelo aos demais. Com relação ao serviço dos doentes: (...) farão suas camas, porão em ordem os dormitórios, apresentarão os remédios e darão o almoço. No correr do dia, uma vigilância contínua sobre os doentes para atenderem aos seus menores reclamos, o alimento nas horas marcadas, as poções quando tiverem sede, com algumas pastilhas que Ihes adocem a boca. Ao anoitecer, ás 7 horas, deitar todos os doentes, servidos com um pouco vinho e com algumas doçuras para os que possam necessitar de noite. Das 8 horas em diante, vigia uma Irmã em todas as salas, pronta a acudir ao menor gemido ou chamado ${ }^{(8)}$.

Os rituais de cuidado iam se construindo numa base voltada para a prática do cuidar vivenciada pelas irmãs no cotidiano dos hospitais e dos domicílios, orientadas inicialmente por Luisa de Marillac e Vicente de Paulo, através de cartas, regulamento e transmissão verbal umas às outras, dando origem ao que seria, posteriormente, denominado de técnicas de enfermagem, organizadas numa base científica de cuidar, preconizada por Florence Nightingale.

\section{FLORENCE NIGHTINGALE E O RITUAL CIENTíFICO DO CUIDAR}

Quase dois séculos depois, no dia 12 de maio de 1820, durante uma viagem que Edward e Francis Nightingale realizavam pela Europa, nasce uma de suas filhas que recebeu o nome de Florence em virtude do nascimento ter acontecido na cidade de Florença $\mathrm{a}^{(9)}$. Por ter nascido em uma família rica e educada, viveu a adolescência participando de uma sociedade aristocrática, tendo tido a oportunidade de estudar diversos idiomas, matemática, religião e filosofia ${ }^{(10)}$. Extremamente religiosa, desejava mesmo era fazer "trabalho de Deus" - ajudar os pobres, os doentes e os menos dotados, amenizando-Ihes o sofrimento e a degradação $0^{(11)}$.
Florence Nightingale é considerada a fundadora da Enfermagem moderna em todo o mundo, obtendo projeção maior a partir de sua participação como voluntária na Guerra da Criméia ${ }^{(11)}$, em 1854, quando com 38 mulheres (irmãs anglicanas e católicas) organizou um hospital de 4000 soldados internos, baixando a mortalidade local de $40 \%$ para $2 \%$. Com o prêmio recebido do governo inglês por este trabalho, fundou a primeira escola de enfermagem no Hospital St. Thomas - Londres, em 24/06/1860.

Os fundamentos que nortearam a criação da escola de enfermagem foram originados também, de suas experiências anteriores a guerra, ou seja, sua educação aristocrática que lhe permitiu ter acesso a vários idiomas, a matemática, religião e filosofia ${ }^{(12)}$ e seu estágio de três meses no Instituto de Diaconisas de Kaiserswerth/Alemanha, onde aprendeu os primeiros passos da disciplina na enfermagem (regras e horários rígidos, religiosidade, divisão do ensino por classes sociais). A organização do Instituto de Diaconisas instituída pelo pastor luterano Theodor Fliedner e sua esposa Frederika muito se assemelhava àquela preconizada pelas Irmãs de Caridade de São Vicente de Paulo, estando mais preocupados em formar o caráter de suas alunas do que em ministrar-Ihes conhecimentos específicos de enfermagem ${ }^{(13)}$.

Um fato que é pouco reforçado pelos historiadores é o de que Florence Nightingale conheceu e apreendeu o trabalho desenvolvido pelas Irmãs de Caridade de São Vicente de Paulo em Paris, no Hôteldieu, onde acompanhou o tipo de trabalho assistencial e administrativo que realizavam, suas regras, sua forma de cuidar dos doentes, fazendo anotações, gráficos e listas das atividades desenvolvidas, e aplicou 0 mesmo questionário, que já havia distribuído nos hospitais da Alemanha e Inglaterra, tendo aprofundado seus estudos; a sua organização(14).

Num segundo momento, Florence Nightingale retornou a este hospital por mais um mês, vestindo com o hábito das irmãs, para sentir mais próximo o seu carisma, apenas residindo em casa separada. Possivelmente, o convívio com as regras de conduta das Irmãs de Caridade e as Senhoras da Confraria a influenciaram intimamente na construção do seu modelo de enfermagem.

Em 1854, com a Guerra na Criméia, a Grã-Bretanha lutava junto com a França ao lado dos aliados turcos em sua guerra contra a Rússia. Mais uma vez, as contingências aproximam Florence Nightingale das irmãs de caridade, só que agora de forma indireta. As irmãs já estavam em Constantinopla desde 1839, desenvolvendo seu trabalho nos hospitais, e por ocasião da Guerra foram enviadas por solicitação do governo francês para os hospitais militares e da marinha para prestar cuidados aos enfermos "nem os rigores do inverno, nem a cólera e 0 tifo, nada as assusta, nada as repele"(15). "Ao serviço das ambulâncias e dos hospitais, elas juntaram ainda a visita freqüente aos prisioneiros de todas as nações, e esperavam o desembarque dos navios carregados de doentes e de feridos chegados da Criméia"(15).

Enquanto isso, os hospitais militares ingleses estavam vivendo 0 caos. O exército britânico estava prestes a ser derrotado em virtude da doença, da desorganização, do frio e da fome. A cólera reduziu o exército à inutilidade e as primeiras batalhas da Criméia foram feitas por homens exauridos pela doença e sedentos.

Os jornais ingleses criticavam a administração dos hospitais militares e alguém que conhecia o excelente trabalho das irmãs de caridade nos hospitais militares franceses escreveu no "Times": "PORQUE NÃO TEMOS IRMÃS DE CARIDADE?" O ótimo tratamento que dispensavam aos soldados franceses constituía, sem dúvida, uma novidade para os ingleses, porquanto, algum tempo depois o llustred London News estampou uma ilustração, onde se viam as irmãs trabalhando na enfermaria de seu hospital(16). A conseqüência disto foi que, o Ministro da Guerra necessitava tomar medidas urgentes para reverter a situação, e assim escreve "Na Inglaterra, só conheço uma criatura capaz de organizar e dirigir um plano assim...mas não devo ocultar que, segundo 
penso, o sucesso final ou o fracasso do projeto depende de sua decisão"(16). Esta pessoa era Florence Nightingale.

A partir destas informações, entendo que, ao pensar numa escola de enfermagem, Florence Nightingale deva ter utilizado muito do que havia aprendido com as irmãs de caridade, desde as vastas exigências de caráter moral e espírito religioso feitas às candidatas, a distribuição e controle do tempo destinado ao trabalho hospitalar, curso e folgas, bem como, a admissão de alunas de classes sociais diferenciadas. As de classe elevada (lady nurses) podem ser comparadas às Senhoras da Confraria, que eram preparadas para as atividades de supervisão, direção e organização do trabalho em geral, e as de nível sócio-econômico inferior (nurses) que podem ser comparadas as irmãs de caridade provenientes das aldeias, que eram mais preparadas para o trabalho manual, o cuidado direto, a obediência e a submissão.

As idéias de Florence Nightingale acerca da enfermagem como profissão chocavam-se com a ideologia da era vitoriana, correspondente à prática da enfermagem, ou seja, uma forma de ocupação manual desempenhada por empregadas domésticas. Não obstante, a escola iniciou seu funcionamento tendo por base: a) preparo de enfermeiras para o serviço hospitalar e para visitas domiciliárias a doentes pobres; b) preparo de profissionais para 0 ensino de enfermagem ${ }^{(17)}$. Na seleção das candidatas, as qualidades morais tinham prioridade durante o curso e a disciplina era rigorosa. 0 rigor da escola justificava-se, considerando o que era corrente na época, isto é, quem cuidava dos doentes na Inglaterra eram pessoas imorais e, portanto, o modelo preconizado deveria ser o oposto, o mais próximo possível do que realizavam as associações religiosas, porém laicas.

\section{CONSIDERAÇÕES FINAIS}

A descrição destes movimentos para a construção da enfermagem no mundo indica que seria enganoso atribuir somente às idéias de Florence Nightingale o movimento para criação e desenvolvimento da enfermagem moderna. Não obstante, foi ela quem exerceu maior influência sobre a reforma da enfermagem no mundo e o seu trabalho neste sentido é considerado por todos os autores que tratam sobre a história da enfermagem, como o mais completo. Diríamos que Florence

\section{REFERÊNCIAS}

1. Donahue P. Historia de la Enfermería. St Louis (USa): Mosby Company; 1993

2. Padilha MICS. A mística do silêncio na enfermagem na Santa Casa de Misericórdia do Rio de Janeiro no Século XIX. Pelotas (RS) UFPel; 1998.

3. Castro JCM. Vida de Luiza de Marillac - fundadora das irmãs de caridade. Petrópolis(RJ): Vozes; 1936

4. Ausart AJS. Vicent de Paul (l'espirit de) ou modèle propocé a transles ecclisiastiques dans ses virtus, cés actions et ces paroles. Paris;1780.( mimeo)

5. Vaessen PG. Santa Luiza de Marillac suas filhas e suas Senhoras de Caridade. Salvador(BA): Ed. Mensageiros de Fé;1949.

6. Foucault M. Microfísica do poder. $3^{\mathrm{a}}$ ed. Rio de Janeiro (RJ): Graal; 1982.

7. Focault M. Vigiar e punir. $6^{\mathrm{a}}$ ed. Petrópolis (RJ): Vozes;1987.

8. Boavida PLG. Vida da venerável Luiza de Marillac. Rio de Janeiro (RJ): Typ. Besnard Frères; 1915.

9. Woodham-Smith C. Florence Nightingale. New York (USA)
Nightingale deu voz ao silêncio daqueles que realizavam o cuidado de enfermagem e que, provavelmente, não tinham noção da importância daqueles rituais que indicavam uma prática de enfermagem já organizada, tanto no cotidiano das ações de enfermagem como na distribuição do trabalho por classes sociais(2).

Proporcionou o significado aos silêncios que haviam na prática de enfermagem, através da Escola e de tudo que escreveu sobre a forma de cuidar do outro, que até então era envolto em regulamentos e correspondências internas, executadas apenas por aquelas que faziam parte das associações específicas, na maioria das vezes religiosas, com espírito vocacional de servir o outro por amor a Deus e não com o espírito e o desejo de construir uma profissão.

O momento em que Florence Nightingale cria a profissão de enfermagem na Inglaterra coincide com as transformações evidenciadas por Michel Foucault no ambiente hospitalar, estabelecendo o vínculo entre 0 saber de enfermagem e o saber médico, numa situação de subordinação, considerando que até o século XVIII quem dominava 0 espaço hospitalar eram as irmãs de caridade. Quando o médico percebe que o hospital é um campo de saber e conseqüente poder, ele assume este espaço e as irmãs de caridade 0 cedem passivamente, porém continuam assegurando-o através do poder silencioso do cuidar e do domínio do ambiente e das chaves. Florence Nightingale com seus conhecimentos e crença de que a enfermagem poderia ser uma profissão reconhecida, valorizada e exercida por mulheres de várias classes sociais, propõe a retomada deste espaço no sentido de coletivizá-lo.

Ao nosso ver, esta configuração de espaços no ambiente hospitalar consolidou os fundamentos que serviram de base para a atual prática de enfermagem que merece novas e constantes reflexões acerca de sua construção, principalmente com relação aos aspectos que compõem o ideário da enfermagem até os nossos dias os quais, muitas vezes influenciam na formação dos futuros profissionais de enfermagem, priorizando os ideais de fraternidade e altruísmo, sobre o fato da enfermagem construir-se como uma profissão com bases científicas e com a especificidade de cuidar do outro.
McGrawHill Book;1951

10. Graaf KR. Arte e ciência de la enfermeria humanista: Florence Nightingale. In: Marinner A. Modelos y teorias de enfermería. Barcelona (ESP): Rol; 1989. [s.p.].

11. Nash R. Um esboço da vida de Florence Nightingale. Rio de Janeiro (RJ): EEAN/UFRJ; 1980

12. Strachey L. Eminent Victorians. London (UK): Books; 1986.

13. Stewart I. The education of nurses. New York (USA): The Camillan; 1950.

14. Brown P. Florence Nightingale. São Paulo (SP): Globo; 1993.

15. Milon M.Histoire des filles de la charité. Annales de la congregation de la misión. Paris (FRA): 1932.

16. Seymer R L. Florence Nightingale. São Paulo (SP): Melhoramentos; [s.d.]

17. Alcântara G. A enfermagem moderna como categoria profissional: obstáculos à sua expansão na sociedade brasileira [tese de livre docência]. Ribeirão Preto(SP): Escola de Enfermagem, Universidade de São Paulo;1963. 